\title{
A inserção da educação para as relações étnico- raciais nos cursos de licenciatura da UFBA
}

\author{
Renata Veras', Erika Chaves', Daiane Silva1, Mariana Prates', Sheyla \\ Fernandes $^{2}$ \\ 1 Universidade Federal da Bahia, Brasil | renatameiraveras@gmail.com; \\ erikachaves2003@yahoo.com.br; dai.luz.dai@gmail.com; \\ marianapratesufba2017@gmail.com | https://orcid.org/0000-0002-1681-1401; \\ https://orcid.org/0000-0001-5196-270X; https://orcid.org/0000-0002-8177-5160; \\ https://orcid.org/0000-0003-3031-7191 \\ 2 Universidade Federal de Alagoas, Brasil | sheylacsfernandes@msn.com | \\ https://orcid.org/0000-0003-4759-1314
}

\begin{abstract}
Resumo: A formação de professores em uma perspectiva decolonial requer refletir sobre a condição dos sujeitos subalternizados pela colonialidade às lógicas educativas hegemônicas e eurocêntricas. Nesse sentido, questiona-se: de que maneira a educação para as relações étnico-raciais vêm sendo inseridas no currículo dos cursos de licenciatura da Universidade Federal da Bahia? O objetivo deste estudo é analisar a inserção da educação para as relações étnico-raciais nos currículos dos 30 cursos de licenciatura da Universidade Federal da Bahia. Para tanto, foi identificado que dos 1004 componentes ofertados na matriz obrigatória desses cursos, 27 continham temáticas voltadas para a questão racial. Trata-se de um estudo transversal, exploratório de caráter qualitativo. Os dados foram analisados por meio de classificação hierárquica descendente e de árvores de similitudes com o apoio do software IRAMUTEQ. O curso de História foi o que mais ofertou componentes dessa natureza, enquanto os de Ciências Biológicas, Computação, Matemática e Química foram os que tiveram menor oferta. A análise da classificação hierárquica descendente e de similitude permitiu revelar que os temas mais frequentes estavam relacionados à história do Brasil, contemplando a educação e a cultura. Ressalta-se a importância de transversalizar na formação docente temas como: diversidade étnico-racial no Brasil, suas contribuições sociopolíticas, econômicas, culturais, educacionais e artísticas, bem como a reflexão crítica acerca de discriminações e de opressões raciais. A iniciativa de explorar o tema numa perspectiva decolonial e transgressora tem um potencial de gerar mudanças na formação cidadã desde a educação infantil, em prol de uma sociedade mais justa e menos desigual.
\end{abstract}

Palavras-chave: Currículo; Licenciatura; Educação Decolonial; Étnico-racial; Universidade.

The Study of Education for Ethnic-racial Relations in Undergraduate Courses at UFBA

Abstract: Teacher education in a decolonial perspective requires reflecting on subjects subordinated by coloniality to hegemonic and Eurocentric educational logics. In this sense, the question arises: how has education for ethnic-racial relations been included in the curriculum of undergraduate courses at the Federal University of Bahia? The aim of this study is to analyze the inclusion of education for ethnic-racial relations in the curricula of undergraduate courses at the Federal University of Bahia. Therefore, it was identified that of the 1004 components offered in the mandatory matrix of these courses, 27 contained themes focused on the racial issue. This is a cross-sectional, exploratory, qualitative study. Data were analyzed using descending hierarchical classification and similarity trees with the support of the IRAMUTEQ software. The History course was the one that most offered components of this nature, while those in Biological Sciences, Computing, Mathematics and Chemistry were the ones with the lowest offer. The analysis of the descending hierarchical classification and similarity revealed that the most frequent themes were related to the history of Brazil, including education and culture. The importance of mainstreaming in the teacher education themes such as: ethnic-racial diversity in Brazil, its socio-political, economic, cultural, educational and artistic contributions, as well as critical reflection on racial discrimination and oppression is emphasized. The initiative to explore the topic in a decolonial and transgressive perspective has the potential to generate changes in citizen education since early childhood education, in favor of a more just and less unequal society.

Keywords: Curriculum; Initial Teacher Formation; Decolonial Education; Ethnic-racial; University. 


\section{Introdução}

A Universidade passou por mudanças significativas na última década. Os movimentos sociais, especialmente o Movimento Negro, foram fundamentais na busca por direitos educacionais visando a um modelo equitativo em uma sociedade bastante desigual como é o Brasil (Oliveira, 2018). É importante destacar que os povos originários e de etnias que não fossem europeias, principalmente negros e indígenas, tiveram direitos humanos básicos negados desde os primórdios da formação da sociedade brasileira até a sua constituição atual. Assim, é necessário que medidas sejam tomadas no sentido de reparar danos psicológicos, materiais, sociais, políticos e educacionais sofridos por estes grupos, advindos da colonização, frente às políticas de branqueamento da população (Brasil, 2004).

Podemos citar alguns avanços no campo das políticas públicas com a Lei 10.639, de 9 de janeiro de 2003, que determinou a inclusão obrigatória da "História e Cultura AfroBrasileira" na educação básica (Brasil, 2003). Posteriormente, com a Lei 11.645, promulgada em 10 de março de 2008, que alterou o artigo 26-A da Lei 9.394, de 20 de dezembro de 1996 (Brasil, 1996), mais um progresso ocorreu ao acrescentarem os estudos sobre a população indígena. Outro destaque no esteio das políticas educacionais foram As Diretrizes Curriculares Nacionais (DCN) para a Educação das Relações ÉtnicoRaciais para o Ensino de História e Cultura Afro-Brasileira e Africana em 2004 (Brasil, 2004), as DCN para a Educação Escolar Indígena na Educação Básica (Brasil, 2012) e as DCN para a Formação de Professores Indígenas em cursos de Educação Superior e de Ensino Médio (Brasil, 2015). Ademais, a Lei 12.228, de 20 de julho de 2010, instituiu que o Poder Executivo Federal incentivará as instituições de ensino superior a incorporar temas como pluralidade étnica e cultural da sociedade brasileira nos currículos das licenciaturas (Brasil, 2010).

Cabe destacar que as ações afirmativas para acesso e permanência nas universidades públicas foram impulsionadas pela Lei 12.711, promulgada em 29 de agosto de 2012 , denominada Lei de Cotas (Brasil, 2012), e dos programas de assistência estudantil. A Universidade Federal da Bahia (UFBA) foi uma das pioneiras em adotar cotas raciais e sociais, a partir de 2005, com sucesso (Queiroz \& Santos, 2006), inclusive, como dispositivo para ingresso às graduações mediante cotas específicas para remanescentes de comunidades quilombolas e aldeados indígenas.

Para Ristoff (2014), existe uma maior concentração de estudantes autodeclarados negros em cursos de licenciatura em todo o Brasil. Por essa perspectiva, defende-se que os cursos de licenciatura são basilares para a promoção da educação para as relações étnico-raciais. A inserção curricular desta temática nesses cursos poderá possibilitar que os futuros docentes atuem como mobilizadores de espaços escolares mais críticos, democráticos e menos racistas. Sendo assim, essa discussão gerou a questão de pesquisa: de que maneira a educação para as relações étnico-raciais vêm sendo inseridas no currículo dos cursos de licenciatura da UFBA? Para responder a esta questão, a pesquisa teve como objetivo analisar como a UFBA aborda a temática étnico-racial nos cursos que formam profissionais da educação.

\section{O Processo Histórico de Escolarização Colonial no Brasil}

No âmbito escolar, desde o período colonial, negros escravizados eram impedidos de acessar estabelecimentos de ensino, quando estes existiam (Nascimento, 1940). Percebese que, em 1759, a soma dos alunos de todas as instituições jesuíticas não atingia $0,1 \%$ da população brasileira, pois delas estavam excluídas as mulheres ( $50 \%$ da população), os escravos (40\%), os negros livres, os pardos, filhos ilegítimos e crianças abandonadas (Marcílio, 2005). Aos indígenas era reservada a educação jesuítica para o catecismo que tinha como principal objetivo civilizá-los e convertê-los (Castro, 2002). 
Com a publicação do Decreto $1.331 / 1854$, que proibia a admissão de negros nas escolas públicas brasileiras, foi reafirmada a exclusão deles perante à educação. Contudo, em 1871, a Lei do Ventre Livre estabeleceu que os filhos de mulheres escravizadas, a partir dessa data, eram livres e deveriam ser educados (Gonçalves \& Silva, 2000), apesar de isentar os escravagistas de qualquer responsabilidade quanto a essa escolarização (Fonseca, 2000).

Em 1878, foi promulgado o Decreto Leôncio de Carvalho que criou cursos noturnos para livres e libertos (Peres, 1995). No entanto, em síntese, as escolas noturnas tiveram em seu seio fortes mecanismos de exclusão baseados em parâmetros raciais (eram excluídos os negros mesmo que estes fossem libertos e livres) e parâmetros de classe ao excluírem os escravizados (Gonçalves \& Silva, 2000).

Esses decretos e medidas contribuíram para o racismo estrutural no seio da sociedade até os dias atuais, fazendo com que parcelas da sociedade reagissem para reparar a desigualdade decorrente dessa época. Essas normativas também denotam a natureza política do racismo, cuja estrutura é proveniente de uma conjuntura social forjada em exclusão racial que normaliza "as relações políticas, econômicas, jurídicas e até familiares" (Almeida, 2018, p. 38), performam as formas de conviver e compreender as diferenças.

Com a promulgação da Constituição de 1988, o país procurou firmar ainda mais a condição de Estado democrático de direito, realçando no texto constitucional a dignidade da pessoa humana e a cidadania, no intuito de criar mecanismos para a mudança gradual de uma realidade marcada por racismo (Brasil, 2003).

É preciso abrir o debate acerca do conceito de raça nesse momento, uma vez que para Quijano (2002) se trata de uma invenção que nada tem a ver com processos biológicos. Para esse autor, a criação desse conceito tem um papel fundamental no desenvolvimento do capitalismo moderno a partir do século XIX. Mas antes disso, esse conceito operou a inferioridade de grupos que não representavam as características do europeu, imprimindo diferenciações no trabalho, no salário, na produção cultural e de conhecimentos. Este último, Quijano (2002) nomeia como colonialidade do saber, uma vez que outros tipos de conhecimentos, que não a europeia, seriam repreendidas, negando o legado intelectual e histórico de outros povos, fazendo-os reduzirem à categoria de primitivos e irracionais por pertencerem a outra "raça" (Oliveira, 2018).

Assim, de acordo com Oliveira (2018), é fundamental que haja no campo da educação uma insurgência propositiva, criando novas condições sociais, políticas, culturais e de pensamento e destaca-se aqui a importância da formação de professores. Essa perspectiva de educação decolonial requer pensar a partir dos sujeitos que são subalternizados pela colonialidade às lógicas educativas hegemônicas centradas na lógica europeia.

\section{Metodologia}

Este estudo foi realizado a partir da pesquisa qualitativa que, segundo Godoy (1995), pode levar o pesquisador a diferentes possibilidades na realização de sua investigação, o que o permitiria criar caminhos a serem percorridos. A possibilidade eleita, neste caso, é a pesquisa documental, que está centrada na análise dos currículos prescritos dos cursos de licenciatura da UFBA, especificamente, as ementas dos componentes curriculares desses cursos.

Partindo do pressuposto defendido por Goodson (2007), que compreende currículos como construtos sociais e mecanismos de reprodução das relações de poder existentes na sociedade, elegeu-se a abordagem qualitativa da pesquisa como escolha metodológica mais apropriada. 
Segundo Minayo (2016), a pesquisa qualitativa aprofunda-se no mundo dos significados das ações humanas, possibilitando adentrar "[...] o universo de significados, motivos, aspirações, crenças, valores e atitudes, o que corresponde a um espaço mais profundo das relações, dos processos e dos fenômenos que não podem ser reduzidos à operacionalização de variáveis" (p.22). Portanto, contribui para identificar elementos determinantes e constituintes do currículo.

Para esse estudo foi realizada a análise em trinta currículos, acessados via website do sistema acadêmico institucional. A fase inicial dessa pesquisa foi o levantamento dos componentes curriculares que dispõem de ementas para consulta pública. Assim, buscouse analisar dentre essas ementas quais eram obrigatórias e cujos conteúdos se relacionam com a temática educação para as relações étnico-raciais e/ou diversidade e/ou cultura africana e/ou indígena e correlatos.

O software IRAMUTEQ (Interface de R pour Analyses Multidimensionnelles de Textes et de Questionnaires) contribuiu como acessório de pesquisa para organização e tratamento de dados, a partir da opção dos recursos: análise de similitudes e classificação hierárquica descendente (CHD). Este é um software livre que permite fazer diferentes análises estatísticas sobre o corpus textuais e tabelas que vão desde lexicografia básica, que envolve a tematização e o cálculo de frequência de palavras, até análises multivariadas. Por meio dessas análises de semelhanças, pode-se detectar o núcleo central da pesquisa, ajudando assim na identificação do contexto, bem como na especificidade de palavras, além de outras possibilidades, como estudo de gráficos (Camargo \& Justo, 2013).

Segundo estes autores, o método possibilita diferentes tipos de análises textuais, desde as bem simples como lexicografia básica que inclui a tematização e o cálculo de repetição de palavras, até análises diversas e mais complexas como: classificação hierárquica descendente, análise pós-factorial de correspondências e análise de similitude. Assim sendo, esse estudo utilizou esse método para apresentar de forma organizada, simples e de fácil compreensão as análises lexicográficas que foram utilizadas (Camargo \& Justo, 2013).

No software IRAMUTEQ existem dois tipos de grandes análises: Corpus Textual e Análise de Matrizes; onde a primeira se refere à análise de dados de material verbal transcrito e a segunda permite que se faça uma investigação que envolva diferentes variáveis, contudo nesse estudo utilizaremos apenas análise de Corpus Textual.

De acordo com Camargo e Justo(2013), esses dois grupos de análises se subdividem em outros grupos específicos de estudo, deste foram utilizados: o de classificação hierárquica descendente (CHD) e o similitude. Segundo o autor, o CHD é uma das análises mais importantes do IRAMUTEQ, pois ela obtém vários segmentos de textos (ST) ao mesmo tempo e apontam vocabulários análogos entre si, e vocabulários diferentes sobre outros textos, possibilitando obter classes de ST, que apresentem vocabulário semelhante entre si, além de vocabulário diferente dos ST de outras classes, então a partir dessas análises o software estrutura os dados em um dendrograma que explana de modo claro as relações de classes.

Enquanto o grupo específico da análise de similitude permite identificar simultaneamente a ocorrência entre as palavras, ou seja, uma conexão entre elas. Além de permitir a identificação dos elementos comuns e as particularidades em função das variáveis que foram mencionadas no estudo (Camargo \& Justo, 2013).

\section{Resultados}

Nesse estudo, foram encontrados 27 componentes curriculares de 1004 analisados ao total em 30 currículos de licenciatura da UFBA que possuem em suas ementas e/ou conteúdos a abordagem da temática étnico-racial construída de modo ora direto, como por exemplo, a disciplina TEAB24 (Laboratório de Práticas Pedagógicas I), que apresenta em sua ementa a necessidade da "aplicação articulada em práticas laboratoriais dos 
conteúdos didático pedagógicos e específicos do fazer teatral no contexto escolar, com ênfase na abordagem de temas relacionados à educação para relações étnico-raciais"; ora indireto, tal como o componente curricular EDCD59 (Educação, Identidade e Pluralidade Cultural) que possui em sua ementa questões referentes à discriminação/preconceito, cultura, identidade, memória, tradições e saberes populares.

A análise do conteúdo dessas ementas se deu a partir das DCN para a Educação das Relações Étnico-Raciais e para o Ensino de História e Cultura Afro-Brasileira e Africana, publicadas em março de 2004, assim como também da Lei 11.645/2008, que prevê a obrigatoriedade de inclusão no currículo da educação básica, do ensino da temática "História e Cultura Afro-Brasileira e Indígena". Os parâmetros de identificação relacional dos conteúdos dessas ementas com a DCN para a Educação das Relações Étnico-Raciais e com a referida Lei $11.645 / 2008$, foram, no caso da DCN, os itens pertencentes à subseção de "ações educativas de combate ao racismo e à discriminação", e no caso da Lei 11.645/2008, em seu artigo $1^{\circ}, \S^{\circ} 1^{\circ}$ e $2^{\circ}$, que versam sobre a inclusão no conteúdo programático da educação básica, dos aspectos sociais, econômicos e políticos resultados das contribuições africana e indígena para a história do Brasil; explicitam a necessidade de estudo dos variados aspectos histórico e culturais que compõem a formação da população brasileira à luz desses dois grupos étnicos e reiteram que os conteúdos concernentes à história afro-brasileira e indígena devem ser ministrados em todo o âmbito do currículo escolar.

Os componentes curriculares com conteúdos correlatos à temática estudada foram elencados na Tabela 1, bem como os respectivos cursos que o ofertam.

Quadro 1. Componentes curriculares

\begin{tabular}{l}
\hline Código e nome da disciplina \\
\\
1. EDCA02 - Organização da \\
Educação Brasileira II
\end{tabular}

2. EDC238 - Capoeira I

3. EDC283 - Currículo

4. EDCA11 - Didática e Práxis Pedagógica I

5. EDCD59 - Educação, Identidade e Pluralidade Cultural

6. EDCA05 - História da Educação Brasileira

\section{Cursos que ofertam os componentes}

Ciências Biológicas Diurno e Noturno; Ciências Naturais Diurno; Ciências Sociais Diurno; Educação Física Diurno; Filosofia Diurno, História Diurno e Noturno; Matemática Diurno e Noturno, Química Noturno; Licenciatura em Desenho e Plástica Diurno; Música Diurno; Música Piano Diurno; Dança Diurno e Noturno.

\section{Educação Física Diurno.}

Ciências Naturais Diurno.

Filosofia Diurno, Computação Noturno, Física Diurno e Noturno, Geografia Diurno e Noturno, Letras em Inglês Diurno e Noturno, Letras Vernáculas em Inglês Diurno, Letras Português Diurno e Noturno, Desenho e Plástica Diurno, Música Diurno, Música Piano Diurno, Dança Diurno e Noturno, História Diurno e Noturno.

Educação Física Diurno.

Pedagogia Diurno e Noturno 


\begin{tabular}{|c|c|c|}
\hline \multicolumn{2}{|c|}{ Código e nome da disciplina } & \multirow{2}{*}{$\begin{array}{l}\text { Cursos que ofertam os componentes } \\
\text { Pedagogia Diurno e Noturno }\end{array}$} \\
\hline 7. & $\begin{array}{l}\text { EDC302 - Metodologia do } \\
\text { Ensino da Língua Portuguesa }\end{array}$ & \\
\hline 8. & $\begin{array}{l}\text { DANA05 - MID: Estudos } \\
\text { Crítico-analíticos I }\end{array}$ & Dança Diurno. \\
\hline 9. & $\begin{array}{l}\text { DANA69 - Estudos Críiticos } \\
\text { Analíticos em Dança II }\end{array}$ & Dança Noturno. \\
\hline 10. & $\begin{array}{l}\text { EBA010 - História da Arte } \\
\text { Brasileira }\end{array}$ & Desenho e Plástica Diurno. \\
\hline 11. & FCH124 - Antropologia I & Ciências Sociais Diurno. \\
\hline 12. & FCH014 - História Antiga I & História Diurno e Noturno. \\
\hline 13. & $\begin{array}{l}\text { FCHG06 - História Indígena e } \\
\text { do Indigenismo }\end{array}$ & História Diurno e Noturno. \\
\hline 14. & FCHD90 - História da África I & História Diurno e Noturno. \\
\hline 15. & FCHD91 - História da África II & História Diurno e Noturno. \\
\hline 16. & FCH018 - História Moderna I & História Diurno e Noturno. \\
\hline 17. & FCH185 - História do Brasil II & História Diurno e Noturno. \\
\hline 18. & FCH196 - História da Bahia II & História Diurno e Noturno. \\
\hline 19. & FCH190 - História do Brasil III & História Diurno e Noturno. \\
\hline 20. & GEO084 - Geografia do Brasil & Geografia Diurno e Noturno. \\
\hline 21. & $\begin{array}{l}\text { LETA30 - A Língua Portuguesa } \\
\text { no Brasil }\end{array}$ & $\begin{array}{l}\text { Letras Vernáculas e Inglês Diurno, } \\
\text { Letras Português Diurno e Noturno. }\end{array}$ \\
\hline 22. & $\begin{array}{l}\text { LETA21 - A Literatura Brasileira } \\
\text { e a Construção de } \\
\text { Nacionalidade }\end{array}$ & $\begin{array}{l}\text { Letras Inglês Diurno e Noturno, Letras } \\
\text { Vernáculas e Inglês Diurno, Letras } \\
\text { Português Diurno e Noturno. }\end{array}$ \\
\hline 23. & $\begin{array}{l}\text { MUSC65 - Fundamentos da } \\
\text { Educação Musical II }\end{array}$ & Música Diurno e Música Piano Diurno. \\
\hline 24. & $\begin{array}{l}\text { MUSB76 - Música Brasileira de } \\
\text { Tradição Oral }\end{array}$ & Música Diurno e Música Piano Diurno. \\
\hline 25. & $\begin{array}{l}\text { TEAA21 - História do Teatro no } \\
\text { Brasil e na Bahia }\end{array}$ & Teatro Diurno. \\
\hline 26. & $\begin{array}{l}\text { TEAB24 - Laboratório de } \\
\text { Práticas Pedagógicas I }\end{array}$ & Teatro Diurno. \\
\hline 27. & TEAB32 - Teatro Negro & Teatro Diurno. \\
\hline
\end{tabular}

Fonte: Sistema Acadêmico (SIAC) da UFBA, 2021, disponível em: https://alunoweb.ufba.br/SiacWWW/ListaCursosEmentaPublico.do?cdGrauCurso=01

Pode-se observar que o curso que ofertou maior número de componentes curriculares dessa temática foi o de História, seguido dos cursos de Música e Música - Piano, Dança, Teatro, Letras - Português, Letras Vernáculas e Inglês, Educação Física, Geografia, Ciências Sociais, Filosofia, Pedagogia, Letras - Inglês, Física e Ciências Naturais. Os cursos que menos ofertaram foram os de Ciências Biológicas, Computação, Matemática e Química, que pertencem às áreas de Ciências Biológicas e Ciências Exatas. 
A Classificação Hierárquica gerada pela análise das ementas foi organizada em quatro classes de segmentos de textos, conforme representada na figura 1. A classe 1 representou $28,8 \%$ do corpus, a classe 2 representou 30,4\%, as classes 3 e 4 representaram $21,4 \%$.

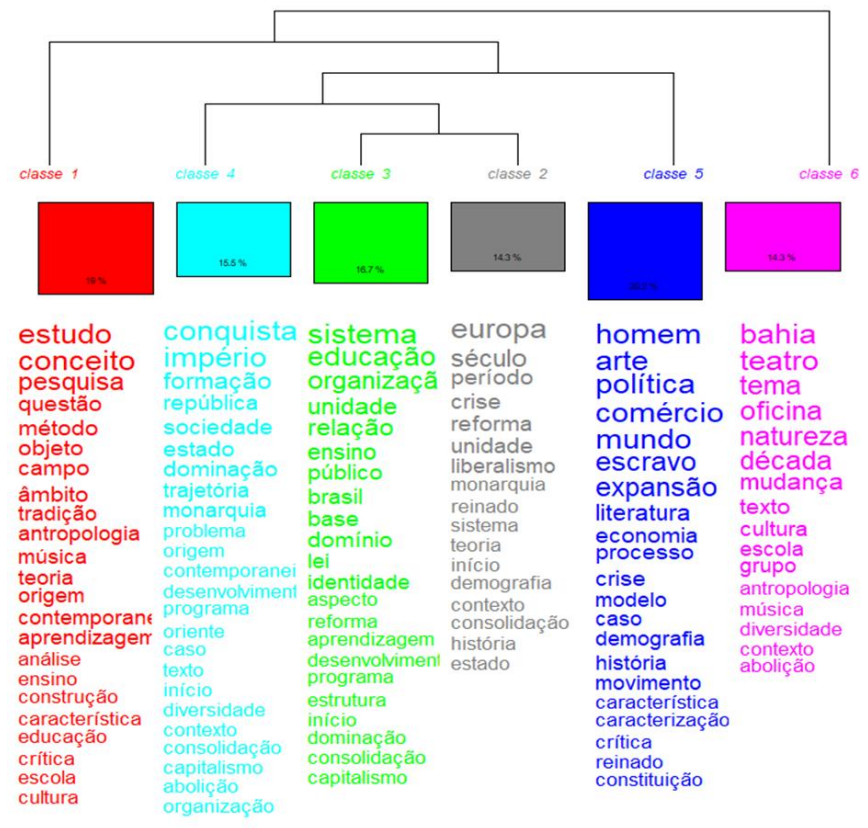

Fig. 1. Dendograma Questões raciais nos cursos de licenciatura da UFBA (Organizado com base no Software IRAMUTEQ, 2021)

A classe 1 representou $19 \%$ dos termos analisados e concentrou palavras que remetem à metodologia e concepções de ensino. As palavras mais frequentes foram "estudo", "conceito" e "pesquisa". Outras com menor frequência foram: "questão", "método", "objeto", "campo", "tradição", entre outras.

A classe 2 teve menor frequência dos termos (14,3\%), enfatiza o contexto histórico, os sistemas políticos e econômicos, tendo a palavra "Europa" como destaque. Também apareceram em menor intensidade outras como: "século", "período", "crise", "reforma", "unidade", "liberalismo", entre outras.

$\mathrm{Na}$ classe 3, com ênfase no tema Sistema de ensino brasileiro, que concentrou 16,7\% dos registros, nota-se a presença de palavras como "sistema", "educação" e "organização" e também "unidade", "relação", "ensino", "público", entre outras.

Representando $15,5 \%$ das ocorrências de palavras, a classe 4 demonstrou ênfase na perspectiva colonial na temática racial com termos: "conquista" e "império" em maior frequência, e "formação", "república", "sociedade", "estado", "dominação", "trajetória" e "monarquia", entre outras.

Com maior concentração de palavras (20,2\%), a classe 5 agrupou termos que tratam do processo histórico para conformação da sociedade no mundo contemporâneo, tais como: "homem", "arte", "política", "comércio", "mundo", "escravo" e "expansão". Em menor frequência também apresentou: "literatura", "economia", "processo", "crise", "demografia", entre outras.

A classe 6 , que junto com a classe 2 teve menor frequência de palavras, com destaque para a temática Arte e Cultura, é composta de palavras como "Bahia", "teatro", "tema", "oficina", "natureza" com maior destaque e outras com menor destaque: "cultura", "escola", "antropologia", "música", "abolição", entre outras. Percebe-se, assim, que há uma ênfase na cultura africana nas ementas de boa parte dos componentes analisados desse grupo. 


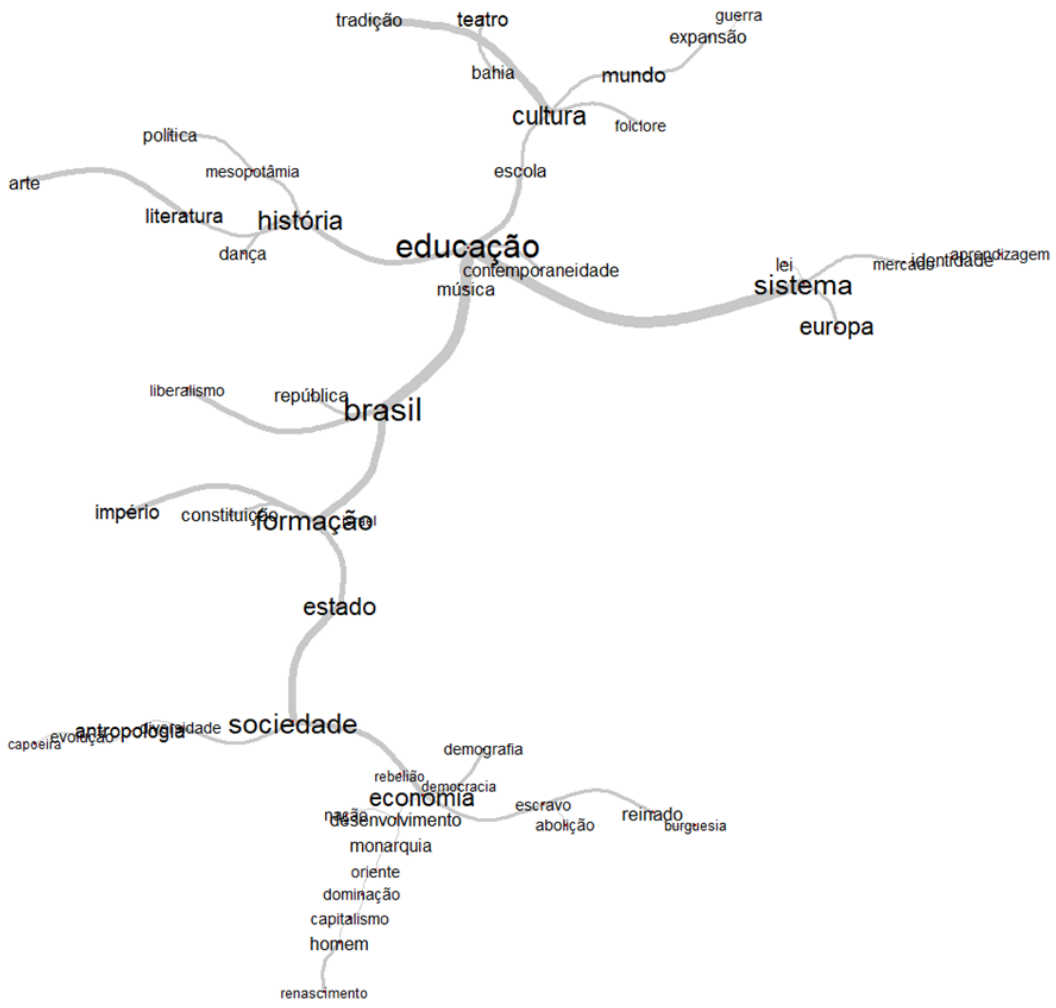

Fig. 2. Análise de similitudes dos temas presentes nas ementas (organizado com base no Software IRAMUTEQ, 2021)

A análise da similitude permitiu visualizar um detalhamento mais acurado dos temas apresentados com maior frequência nas ementas.

Dos temas presentes na árvore de similitude podemos notar que a palavra "educação" concentra a maior relação entre as demais palavras. Existem quatro principais ramificações para grupos: "sistema", "lei" e "Europa"; para "cultura", "teatro", "mundo", "Bahia", "folclore"; para "história", "literatura" e "dança". A quarta ramificação aponta para "Brasil", "república" e "liberalismo" que dá continuidade com outra ramificação importante para três outros eixos: "formação", "sociedade" e "economia", essa última ainda se desenvolve com palavras como "escravo", "abolição", "demografia", "rebelião", "monarquia", "dominação", "capitalismo", entre outras.

\section{Discussão}

A pesquisa se desenvolveu apenas com as disciplinas obrigatórias dos cursos de licenciatura, que com base nas fontes normativas citadas, não pode ser a educação para as relações étnico-raciais uma opção, mas um critério necessário para uma efetiva formação cidadã.

Os resultados apontaram que o curso de História teve o maior número de componentes com essa temática, enquanto os cursos de Ciências Biológicas, Computação, Matemática e Química tiveram menor oferta. Silva, Costa e Silva (2019) analisaram os currículos de 41 cursos de licenciatura em uma instituição de ensino superior em Mato Grosso do Sul. 
Desses cursos analisados, 25 ofertavam essa temática em disciplinas obrigatórias, 9 ofertavam como optativas e 7 cursos não ofertavam. O curso de História também foi o que mais ofertou componentes com a temática enfocando "educação das relações etnicoraciais".

Além disso, a partir da análise de classificação hierárquica descendente e de similitude, pôde-se visualizar uma ênfase considerável no contexto histórico para conformação do Brasil e do povo brasileiro, corroborando com o fato de haver muitos componentes ofertados para o curso de História e sobre história. Ficou evidente que há muitas referências às palavras educação, sociedade e história nas ementas que indicam ênfase na organização do sistema educacional brasileiro. Contudo, é importante que sejam discutidas as heranças culturais que conformam o Brasil, como também o processo de elitização da educação no Brasil a partir da negação de direitos enquanto cidadãos de grupos oprimidos. Para Dias (2012), o combate ao racismo brasileiro só pode ser fomentado na medida em que as escolas (e cursos de formação docente) provoquem mobilizações sociais em diferentes níveis institucionais em prol da criação de programas ou atividades de estímulo à diversidade étnico-racial nos programas de ensino.

Outrossim, palavras como "Europa", "conquista", "escravo" evidenciam que há uma concentração de temas e referências bibliográficas do Norte e não no Sul global, oferecendo a perspectiva da escravidão, o que vai de encontro com a perspectiva decolonial proposta por Quijano (2002).

Por essa razão, Bernardino-Costa (2018) destaca a importância de estudos decoloniais contemporâneos, que buscam o resgate e a evidência das contribuições epistemológicas dos saberes que foram desqualificados e invisibilizados pela colonialidade. Para Candau e colaboradores (2013) a luta por reconhecimento social e cultural é constante e deve passar pela desconstrução do caráter monocultural e etnocentrista nos currículos, resgatar os processos de construção das identidades e integrar as novas configurações culturais, ao reconhecimento e à promoção do diálogo entre os diferentes saberes (Candau, 2013).

Acrescenta-se a essa discussão o apontamento de Ferreira (2019) ao afirmar que estando em disciplinas isoladas, não é possível aprofundar a discussão acerca do que ensinar - e como abordar esses conhecimentos - na educação básica. Por se tratar de tema que deveria perpassar toda formação dos licenciandos, entende-se a pertinência da educação para as relações étnico-raciais em todos os componentes curriculares, com articulação entre eles.

Portanto, incentiva-se a interdisciplinaridade que poderia fornecer soluções alternativas para a complexidade dos fatores sociais e políticos que se revelam na formação de professores, especialmente no que diz respeito a um ensino libertador, proposta baseada no respeito às diferenças.

Essas estratégias se articulam com a perspectiva de que a sala de aula é um espaço multicultural e interseccional, formado por pessoas de diferentes etnias, raças, culturas, crenças, gêneros, sexualidades, classes e histórias de vida. Para poder efetivar essa proposta, Bell Hooks (1994) sugere uma pedagogia pela transgressão e descolonização, com trocas construtivas radicais na forma de ensinar e aprender, pautada pela liberdade de transgredir e transformar.

\section{Considerações Finais}

As questões que abrangem a Educação para as Relações Étnico-Raciais vêm sendo inseridas no currículo dos cursos de licenciatura da UFBA, a partir da oferta de componentes curriculares que versam sobre assuntos como diversidade, etnia, diferença, pluriculturalismo, história da África e do indigenismo, discriminação e preconceito. 
A pesquisa qualitativa, nesse caso do tipo documental, possibilitou a identificação dos cursos que mais ofertam os componentes, assim como dos temas mais trabalhados nessas matérias, que nesse caso se concentrou no curso de História com as matérias mais voltadas à história cultural e educacional do Brasil. A utilização do software IRAMUTEQ permitiu a identificação e agrupamento dos termos por classes, indicando pouca evidência na discussão da temática na perspectiva decolonial e transgressora, a qual não se limita a enxergar a história através das concepções eurocêntricas.

Na segunda década do século XXI, os processos de resistência e ocupação dos espaços de privilégio social, principalmente, pelos negros e indígenas precisam ser incluídos como tema de formação, não cabe mais sua folclorização. Deve-se questionar a escolha dos conteúdos e introduzir nos currículos, de modo transversal, saberes de diversos grupos colonizados, muitas vezes invisibilizados, em contrapartida com a predominância dos estudos europeus, promovendo o diálogo entre eles e apontando que a diferença deve ser afirmada dentro de uma perspectiva crítica e de compromisso com a justiça social.

\section{Referências}

Almeida, S. (2018). O que é racismo estrutural. Belo Horizonte: Letramento.

Bernardino-Costa, J. (2018). Decolonialidade, Atlântico Negro e intelectuais negros brasileiros: em busca de um diálogo horizontal. Sociedade e Estado, 33(1), 117-135.

Brasil (1996). Lei n. 9.394, de 20 de dezembro de 1996. Estabelece as diretrizes e bases da educação nacional. Brasília: Subchefia para assuntos jurídicos, Casa civil. Recuperado de planalto.gov.br/ccivil_03/leis/19394.htm

Brasil (2003). Lei n. 10.639, de 9 de janeiro de 2003. Altera a Lei no 9.394, de 20 de dezembro de 1996, que estabelece as diretrizes e bases da educação nacional, para incluir no currículo oficial da Rede de Ensino a obrigatoriedade da temática "História e Cultura Afro-Brasileira", e dá outras providências. Brasília: Subchefia para assuntos jurídicos, Casa civil. Recuperado de http://www.planalto.gov.br/ccivil_03/leis/2003/l10.639.htm

Brasil (2004). Parecer n. 03 de 10 de março de 2004 do Conselho Nacional de Educação do Ministério da Educação. Recuperado de http://portal.mec.gov.br/dmdocuments/cnecp_003.pdf

Brasil (2008). Lei n. 11.645, de março de 2008. Altera a Lei no 9.394, de 20 de dezembro de 1996, modificada pela Lei no 10.639, de 9 de janeiro de 2003, que estabelece as diretrizes e bases da educação nacional, para incluir no currículo oficial da rede de ensino a obrigatoriedade da temática "História e Cultura Afro-Brasileira e Indígena". Brasília: Subchefia para assuntos jurídicos, Casa civil. Recuperado de http://www.planalto.gov.br/ccivil_03/_ato20072010/2008/lei/l11645.htm

Brasil (2010). Lei n. 12.288, de 20 de julho de 2010. Institui o Estatuto da Igualdade Racial; altera as Leis nos 7.716, de 5 de janeiro de 1989, 9.029, de 13 de abril de 1995, 7.347, de 24 de julho de 1985, e 10.778, de 24 de novembro de 2003. Brasília: Subchefia para assuntos jurídicos, Casa civil. Recuperado de http://www.planalto.gov.br/ccivil_03/_ato20072010/2010/lei//12288.htm

Brasil (2012). Resolução n. 5 de 22 de junho de 2012 do Conselho Nacional de Educação do Ministério da Educação. Recuperado de http://portal.mec.gov.br/index.php?option=com_docman\&view=download\&alias=11074rceb005-12-pdf\&category_slug=junho-2012-pdf\&ltemid=30192

Brasil (2015). Resolução n. 1 de 7 de janeiro de 2015 do Conselho Nacional de Educação do Ministério da Educação. Recuperado de http://portal.mec.gov.br/index.php?option=com_docman\&view=download\&alias=16870-rescne-cp-001-07012015\&category_slug=janeiro-2015-pdf\&Itemid=30192

Camargo, B.V., \& Justo A.M (2013). Tutorial para uso do software Iramuteq. Recuperado em 07 março 2021, de http://iramuteq.org/ documentation/fichiers/tutoriel-portugais-07-03-2021. 
Candau, V. M. (2013). Educação em direitos humanos e formação de professores(as). São Paulo: Cortez.

Castro, E. V. (2002). A inconstância da alma selvagem. São Paulo: CosacNaify.

Dias, L.R. (2012). Formação de professores, educação infantil e diversidade étnico-racial: saberes e fazeres nesse processo. Revista Brasileira de Educação, 17(51).

Ferreira, V. M. (2019). A questão étnico-racial na formação de professores: análise de currículos. Rio de Janeiro: Pallas.

Fonseca, M. V. (2000). Concepções e práticas em relação à educação dos negros no processo de abolição do trabalho escravo no Brasil (1867-1889). Dissertação de Mestrado, Universidade Federal de Minas Gerais, Belo Horizonte, BH, Brasil.

Godoy, A. S. (1995). Introdução à pesquisa qualitativa e suas possibilidades. Revista de Administração de Empresas, 35(2), 57-63.

Gonçalves, L. A. O.; Silva, P. B. G. (2000). Movimento negro e educação. Revista Brasileira de Educação, 15, 134-158.

Goodson, I. (2007). Currículo, narrativa e o futuro social. Revista Brasileira de Educação, 12 (35), 241-252.

hooks, bell (1994). Teaching to transgress. Education as the practice of freedom. Nova York/Londres: Routledge.

Marcílio, M. L (2005). História da escola em São Paulo e no Brasil. São Paulo: Imprensa Oficial.

Minayo, M. C. S., Deslandes, S. F., \& Gomes, R. (2016). Pesquisa Social. Teoria, método e criatividade. Petrópolis: Vozes.

Nascimento, A. (1940). Influência da mulher negra na educação do brasileiro. Em O negro no Brasil - trabalhos apresentados no 2ํ Congresso Afro-Brasileiro (pp. 211-222). Civilização Brasileira.

Oliveira, L.F. (2018). Educação e militância decolonial. Rio de Janeiro: Editora Selo Novo.

Peres, E. T., (1995). "Tempo da Luz": os cursos noturnos masculinos de instrução primária da biblioteca pelotense (1875-1915). Dissertação de mestrado, Universidade Federal do rio Grande do Sul, Porto Alegre, RS, Brasil.

Queiroz, D. M., \& Santos, J. T. (2006). Sistema de cotas: um debate. Dos dados à manutenção de privilégios e de poder. Educação \& Sociedade, 27(96), 717-737.

Quijano, A. (2002). Colonialidad del poder, eurocentrismo y America Latina. [Colonialidade do poder, eurocentrismo e América Latina]. Clacso.

Ristoff, D. (2014). O novo perfil do campus brasileiro: uma análise do perfil socioeconômico do estudante de graduação. Revista da Avaliação da Educação Superior, 19(3),723-747.

Silva, F. L., Costa, A.F.G, \& Silva, T. P. (2019). As relações etnico-raciais e os currículos dos cursos de licenciatura de uma universidade do Mato Grosso do Sul. Colloquium Humanarum, 16(3), 76-88. 